\title{
A Model for the Management of Female Sexual Dysfunctions
}

\section{Modelo para abordagem das disfunções sexuais femininas}

\author{
Lúcia Alves da Silva Lara ${ }^{1}$ Sandra Cristina Poerner Scalco ${ }^{2}$ Júlia Kefalás Troncon ${ }^{1}$ Gerson Pereira Lopes ${ }^{3}$
}

${ }^{1}$ Human Reproduction Sector, Department of Gynecology and Obstetrics, Faculdade de Medicina de Ribeirão Preto, Universidade de São Paulo, Ribeirão Preto, São Paulo, Brazil

${ }^{2}$ Medical Outpatient of Gynecology, Violence and STDs, Sexology Ambulatory, Gynecology Department, Hospital Materno Infantil Presidente Vargas - PMPA, Porto Alegre, Rio Grande do Sul, Brazil

${ }^{3}$ Department of Sexual Medicine, Hospital Mater Dei, Belo Horizonte, Minas Gerais, Brazil

Rev Bras Ginecol Obstet 2017;39:184-194.
Address for correspondence Lúcia Alves da Silva Lara, MD, PhD, Faculdade de Medicina de Ribeirão Preto, Universidade de São Paulo, Av. Bandeirantes, 3900, CEP 14049-900 Ribeirão Preto, SP, Brazil (e-mail: luciaalvess@yahoo.com.br).

\begin{abstract}
Keywords

- sexuality

- sexual dysfunction

- female sexual response

Introduction Sexual pleasure is fundamental for the maintenance of health and wellbeing, but it may be adversely affected by medical and psychosocial conditions. Many patients only feel that their health is fully restored after they resume normal sexual activities. Any discussion of sexuality in a doctor's office is typically limited, mainly because of a lack of models or protocols available to guide the discussion of the topic. Objectives To present a model designed to guide gynecologists in the management of female sexual complaints.

Methods This study presents a protocol used to assess women's sexual problems. A semi-structured interview is used to assess sexual function, and the teaching, orienting and permitting (TOP) intervention model that was designed to guide gynecologists in the management of sexual complaints.

Results The use of protocols may facilitate the discussion of sexual issues in gynecological settings, and has the potential to provide an effective approach to the complex aspects of sexual dysfunction in women. The TOP model has three phases: teaching the sexual response, in which the gynecologist explains the physiology of the female sexual response, and focuses on the three main phases thereof (desire, excitement and orgasm); orienting a woman toward sexual health, in which sexual education is used to provide information on the concept and healthy experience of sexuality; and permitting and stimulating sexual pleasure, which is based on the assumption that sexual pleasure is an individual right and is important for the physical and emotional well-being.

Conclusion The use of protocols may provide an effective approach to deal with female sexual dysfunction in gynecological offices.
\end{abstract}

received

November 15, 2016

accepted after revision

January 13, 2017

published online

April 3, 2017
DOI http://dx.doi.org/

10.1055/s-0037-1601435.

ISSN 0100-7203.
Copyright $\odot 2017$ by Thieme-Revinter

Publicações Ltda, Rio de Janeiro, Brazil
License terms

(c) (i) $\ominus$ (\$) 


\section{Resumo}

\section{Palavras-chave \\ - sexualidade \\ - disfunção sexual \\ - resposta sexual feminina}

Introdução O prazer sexual é fundamental para a manutenção da saúde e do bemestar da mulher, mas pode ser afetado negativamente por condições médicas e psicossociais. Em muitos casos, a mulher sente que sua saúde geral é restaurada após retomar sua vida sexual. Porém, a discussão sobre função sexual no consultório do ginecologista é limitada devido à falta de modelos ou protocolos disponíveis para orientar a intervenção neste tema.

Objetivos Apresentar um modelo de intervenção nas disfunções sexuais femininas para ser utilizado pelo ginecologista.

Métodos Foi realizada uma revisão da literatura com levantamento de estudos sobre o manejo das disfunções sexuais femininas nas diferentes culturas. A partir desta revisão, foi elaborado um protocolo que consiste da história clínica e de um modelo de intervenção para orientar os ginecologistas no tratamento das queixas sexuais femininas.

Resultados $\mathrm{O}$ uso de protocolos pode facilitar a discussão sobre questões sexuais pelo ginecologista, e pode fornecer uma abordagem eficaz para lidar com os aspectos complexos da disfunção sexual feminina. O modelo proposto, ensinar, orientar e permitir (EOP), tem três fases: ensinar sobre a resposta sexual, na qual o ginecologista explica a fisiologia da resposta sexual feminina, e se concentra nas suas três principais fases (desejo, excitação e orgasmo); orientar sobre saúde sexual para fornecer informações sobre vivência saudável da sexualidade; e permitir a estimulação do prazer sexual, que é um direito individual e importante para o bem-estar físico e emocional do indivíduo.

Conclusão $\mathrm{O}$ uso de protocolos pode fornecer uma abordagem eficaz para o ginecologista lidar com a disfunção sexual feminina.

\section{Introduction}

Sexual activity is important to the overall health and wellbeing of an individual. ${ }^{1}$ Sexual dysfunction leads to negative effects on interpersonal and social relationships, and on the well-being and the quality of life of women. ${ }^{2}$ Numerous clinical, psychological and social conditions may affect this important aspect of life, and patients may report full recovery only if normal sexual activities are restored. Female sexuality and sexual relations also depend heavily on the mores of each era and society. ${ }^{3-6}$

A Brazilian survey showed that $49 \%$ of women experience sexual dysfunction, and hypoactive sexual desire is the most prevalent disorder. ${ }^{7}$ Paradoxically, the discussion of sexuality with doctors is limited, ${ }^{8}$ both because of perceived taboos $^{9,10}$ and because most residents in Obstetrics and Gynecology (Ob-Gyn) are poorly equipped to address sexual problems. In addition, few models are available to guide a doctor in the discussion of sexual dysfunction. Thus, doctors are aware of less than $50 \%$ of the patients' sexual problems, ${ }^{11}$ even though the patients recognize the importance of discussing such topics with their doctors. ${ }^{12}$

Even though female sexual dysfunction is prevalent, after it is identified, few protocols are available for the management of organic and non-organic sexual complaints. This topic was recently discussed in the context of the lack of effective treatment programs; the gap makes it difficult for gynecologists to discuss possible sexual problems with female patients. ${ }^{13}$ Therefore, most patients have relatively little education and low level of access to information on healthy sexuality; this is a common situation, especially in developing countries. ${ }^{14,15}$

Several validated self-reported and clinician-administered instruments are available for assessing female sexual function in clinical research trials; however ,a lack of protocol for practicing clinicians who are neither trained nor specialized in female sexual dysfunction exists. ${ }^{16}$ Even in countries where physician training includes sexology programs, ${ }^{8}$ most physicians still feel ill-equipped to address sexual problems. ${ }^{17}$ The scarcity of technical and human resources useful in dealing with sexual problems has negative implications for the health of the patients. There is a need for a model to guide gynecologists in their attempts to improve the sexual health of their patients. However, not all populations and healthcare institutions openly discuss sexuality. ${ }^{18}$ Thus, it is essential for healthcare professionals to consider the consequences of sexual repression ${ }^{19}$ in their patients. Many sexual problems can be addressed if a gynecologist provides information on sexuality and the psychological, social, and biological mechanisms of the sexual response. Several types of sexual complaints that do not fulfill the criteria for the diagnosis of sexual dysfunction can be addressed with basic assistance from professionals.

The present work shows step-by-step the protocol used to manage female sexual dysfunction in a gynecologic setting, 
an interdisciplinary service formed by a team of gynecologists, psychologists, a psychiatrist, and physiotherapists, all experts in sexology. An interdisciplinary approach is required for the appropriate assessment of the sexual dysfunction of a person, due to a complex interaction of psychological, social, cultural and physiological processes and one or more factors that may impact on any stage of the sexual response cycle.

\section{Methods}

\section{Assessment of Sexual Dysfunction}

In our Institution, Ob-Gyn residents receive training on female sexual problems, and 5th and 6th-year medical students also receive education on female sexual issues in the gynecologic setting. A systematic approach involving an empathic history-taking, a general physical examination, and a detailed local examination, as well as a prescription of rational investigation is used to manage women with sexual complaints, as shown in -Fig. 1. A semi-structured interview developed based on the female sexual response model $^{20}$ is used to assess female sexual problems ( - Table $\mathbf{1}$ ). However, a brief validated five-question, self-administered instrument may be useful for physicians to screen pre and postmenopausal women regarding hypoactive sexual desire disorder. $^{21}$

The diagnostic of sexual dysfunction is based on the International Statistical Classification of Diseases and Related Health Problems (ICD-10) criteria, $^{22}$ and on the Diagnostic and Statistical Manual of Mental Disorders, 5th edition (DSM-5). ${ }^{23}$ The TOP model, an acronym for teaching (T) the sexual response, orienting $(0)$ women toward sexual health, and permitting $(\mathrm{P})$ and stimulating sexual pleasure is used to promote education. This model is based on dimensions derived from the permission, limited information, specific suggestions, and intensive therapy (PLISSIT) model. ${ }^{24}$

\section{Management of Female Sexual Dysfunction}

General Measures to Treat Female Sexual Problems

The TOP model could help physicians better manage patients who have sexual complaints. In regions where doctors are not trained in sexology, the TOP model can help physicians provide patients with basic information on sex, so that women can become familiar with their sexuality. This model also permits doctors to understand the extent to which a patient comprehends sexual function to a level beyond basic knowledge on reproduction. The use of the TOP model also encourages a doctor to provide information about the sexual response at the physical, psychological, social, and emotional levels, without the use of sex therapy, a field in which not all gynecologists are trained. The TOP model involves intervention at three levels, as shown below.

\section{Teaching ( $T$ ) the Sexual Response}

At this level, patients are given an explanation on genital anatomy, and on the mechanism of some components of the sexual response; desire, arousal, and orgasm. This strategy has been employed in other studies to treat different health problems: ${ }^{25,26}$ i) sexual desire is an appetite or drive that motivates us to engage in sexual behavior. A woman feels sexual desire in three situations: spontaneously (reflecting the natural sexual instinct), when she receives sexual stimulation from her partner, and when engaging in sexual

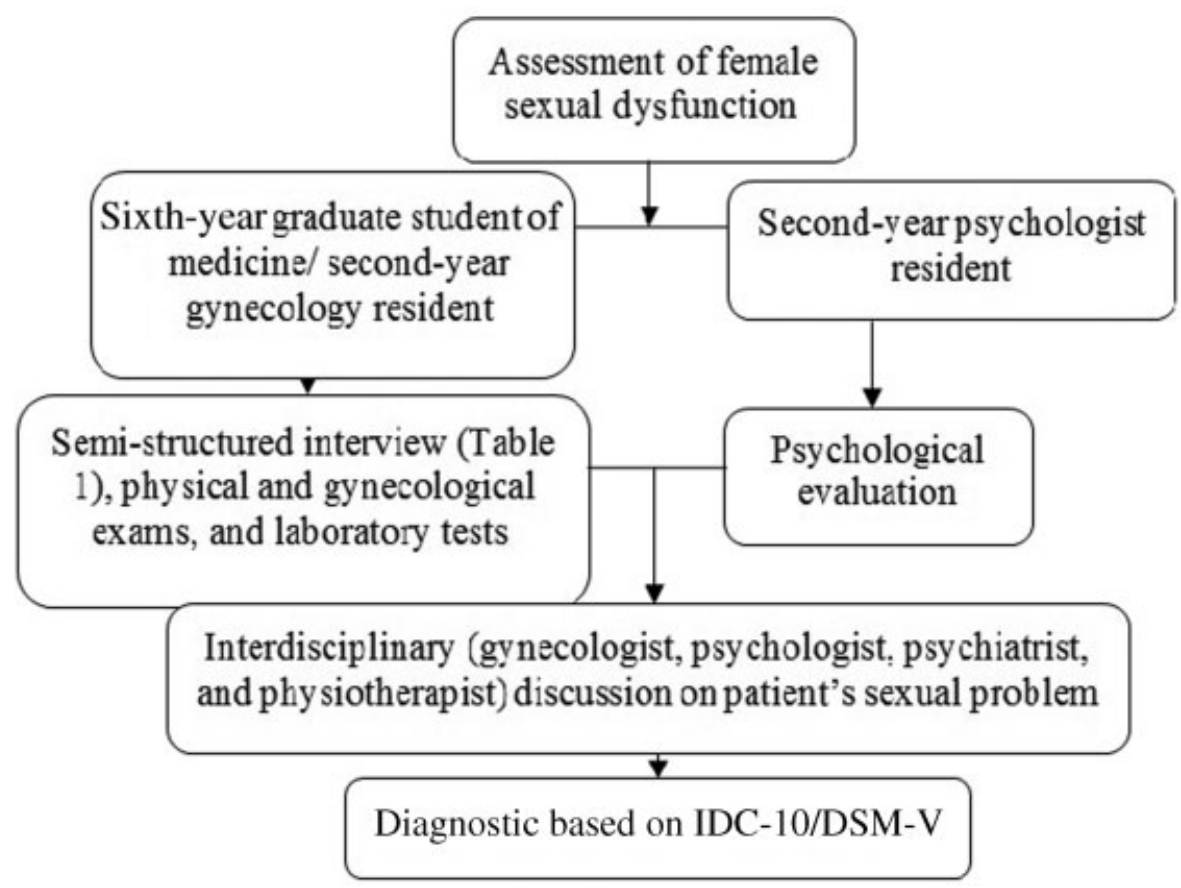

Fig. 1 Proposed algorithm for the management of female sexual dysfunction.

Abbreviations: DSM, Diagnostic and Statistical Manual of Mental Disorders; ICD, International Statistical Classification of Diseases and Related Health Problems. 
Table 1 Semi-structured interview used for the approach of women's sexual complaints

\begin{tabular}{|c|c|}
\hline \multicolumn{2}{|l|}{ Date: / / } \\
\hline \multicolumn{2}{|c|}{$\begin{array}{l}\text { Patient identification: name, age, place of birth, schooling, profession, marital status, time of relationship, religion, current } \\
\text { medications, presence of co-morbidities }\end{array}$} \\
\hline \multicolumn{2}{|c|}{$\begin{array}{l}\text { Partner: age, place of birth, schooling, profession, religion, mood, health status, use of drugs, sexual functioning (erectile } \\
\text { dysfunction, premature ejaculation) }\end{array}$} \\
\hline \multicolumn{2}{|l|}{ Quality of their relationship } \\
\hline \multicolumn{2}{|l|}{ Main sexual complaint } \\
\hline \multicolumn{2}{|c|}{$\begin{array}{l}\text { History of the current sexual complaint: When the problem started, in which situation it occurs, how it evolved, does the partne } \\
\text { know about the complaint? }\end{array}$} \\
\hline \multicolumn{2}{|c|}{ Previous treatments, use of medication } \\
\hline \multicolumn{2}{|c|}{$\begin{array}{l}\text { Gynecological and obstetrical history: menarche, menstrual cycles, parity, route of delivery, contraception, presence of genital } \\
\text { dystopias, genital infections, previous surgeries of the genital tract }\end{array}$} \\
\hline \multicolumn{2}{|l|}{$\begin{array}{l}\text { Sexual history: age of sexarche, } n \\
\text { homosexual relations, extra conju }\end{array}$} \\
\hline \multicolumn{2}{|l|}{ Current emotional status } \\
\hline \multicolumn{2}{|c|}{ Current conditions of the sexual response (in the context of the relationship and/or individual practice) } \\
\hline - Desire & () preserved () impaired \\
\hline - Arousal & () preserved () impaired \\
\hline - Orgasm & () preserved () impaired \\
\hline - Sexual impulse & () yes () no \\
\hline - Sexual fantasies & () yes () no \\
\hline - Masturbation practices & () yes () no \\
\hline - Satisfaction with sexual life & () yes () no \\
\hline \multicolumn{2}{|c|}{ Male partner sexual function assessment } \\
\hline - Affective relationship & () yes () no \\
\hline - Affectionate & () yes () no \\
\hline - Premature ejaculation & () yes () no \\
\hline - Erectile dysfunction & () yes () no \\
\hline \multicolumn{2}{|c|}{ Female partner sexual function assessment } \\
\hline - Affective relationship & () yes () no \\
\hline - Affectionate & () yes () no \\
\hline \multicolumn{2}{|l|}{ Diagnosis } \\
\hline Laboratory tests: blood count, TS & toms \\
\hline
\end{tabular}

Abbreviation: TOP, (T) Teaching the sexual response, Orienting $(\mathrm{O})$ women toward sexual health, Permitting $(\mathrm{P})$ and stimulating sexual pleasure; TSH: thyroid stimulating hormone.

fantasies. ${ }^{27}$ There are many reasons women agree to or instigate sexual activity, and desire may be experienced once the sexual stimuli have triggered arousal; thus, arousal and desire co-occur and reinforce each other. ${ }^{28}$ It is necessary to think about sex to generate sexual fantasies that can lead to desire. Such desire makes a woman receptive to sex, and can cause her to search for sexual relations or to masturbate to obtain sexual pleasure. ${ }^{29}$ ii) Sexual arousal is a pleasurable sensation in the vulva and vagina that causes intumescence of the female genitals because of increased blood flow to this region, and wetness attributable to lubrication of the vagi- na. ${ }^{30}$ If this complex state of arousal is accompanied by positive emotions and thoughts, then sexual desire, along with further arousal, is triggered. Positive sexual experiences provide further motivation to be sexual again. ${ }^{31}$ iii) Orgasm consists of multiple pleasurable contractions of the genitalia, with the first being intense, and the subsequent contractions becoming weaker until they cease. ${ }^{32,33}$ The clitoris becomes erect, and the heartbeat and breathing rate accelerate. An orgasm is reached after stimulation by the movement of the penis inside the vagina, by stimulation of the clitoris, or both. Such stimulation can be caused by sexual activity, 
masturbation, oral sex, a vibrator, or other means. It is likely that all women have the ability to reach orgasm, ${ }^{34}$ but some who do not attain orgasm spontaneously ${ }^{35}$ may be helped by sex therapy. ${ }^{36}$ Women exhibit a gradual resolution of subjective sexual arousal and sexual satiation, but they maintain subjective sexual arousal and desire longer than men after $\operatorname{orgasm}^{37}$

\section{Orienting (0) Women toward Sexual Health}

At this level, information is provided to improve a woman's understanding of the genital anatomy, the physiology of the female sexual function, sexuality and the sexual response, ${ }^{38}$ as well as a description of sexually transmitted diseases (STDs) and contraceptive methods, as follows: $i$ ) sexuality involves affectivity and the search for emotional and physical interactions with partners to achieve sexual pleasure, which can also be attained by sexual self-stimulation, or masturbation; ii) sexuality is formed at an early age, and continues through childhood to adolescence, developing further throughout life; iii) with the aid of a drawing of the genitalia, the professional shows the location of the genital structures, and provides the following explanation: the female genitals consist of the mons pubis, which is covered with hair, the outer labia majora, which are covered with hair, the internal labia minora, which has no hair, and the clitoris, a prominence forming the continuation of the labia minora. The orifice of the urethra and the vaginal introitus are located below the labia; ${ }^{26} i v$ ) the genitals have nerve endings that, if touched, generate a pleasurable sensation and, if the nerves are properly stimulated, sexual pleasure may result; ${ }^{39,40} v$ ) a woman does not always reach orgasm with penetration and the movement of the penis inside her vagina. She can attain orgasm by manipulation of the clitoris during or outside of intercourse; ${ }^{41,42} \mathrm{vi}$ ) all women have the potential to reach orgasm, but some women need to learn how to reach it. Additionally, variations in hormonal receptors, and the levels of neurotransmitters and neuropeptides, may make orgasm difficult for some women; ${ }^{43}$ vii) a woman can feel sexual satisfaction even without reaching orgasm; viii) the most common sex practices are vaginal sex, oral sex, and anal sex; $i x$ ) it is important for a woman to explore her own body and her genital area, especially the clitoris, to better understand the regions associated with sexual pleasure; ${ }^{44} x$ ) in sexual relationships, increase the time spent together as a couple, innovate the sexual repertoire (with different sexual positions, using vibrators, playing out sexual fantasies, etc.), and concentration is important for the woman to reach orgasm; ${ }^{45} x i$ ) the use of a condom protects against STDs and unwanted pregnancies; and $x i i)$ contraceptive methods are discussed.

\section{Permitting $(P)$ and Stimulating Sexual Pleasure}

Historically, female sexuality has been repressed, ${ }^{46,47}$ and many women thus feel guilty about engaging in sexual activities. Some previous studies have emphasized the importance of appropriate discourse facilitated by teaching, ${ }^{48}$ and health care institutions have sought to prevent STDs without compromising the healthy expression of sexuality. ${ }^{49}$
The following arguments have been developed to deal with this problem ${ }^{50}: i$ ) the human body is endowed with physical mechanisms that cause an individual to feel pleasure when eating, having sex, and taking care of him or herself, among other activities. Such pleasures are important for overall health; ii) sex is an important biological and biopsychological function, and everyone has the ability to feel sexual pleasure; iii) sexual pleasure is everyone's right; $i v$ ) all humans deserve sexual satisfaction; and $v$ ) the experience of sexual satisfaction (sexual fulfillment) is important for the emotional and physical well-being, independent of age and some health conditions. ${ }^{51,52}$

The learning session allows the gynecologist to deal with sexual myths and mistaken beliefs about sex, and to reformulate concepts on affectivity and the sharing of sexual experiences. ${ }^{53}$ Successful treatment of sexual complaints suggests that the enjoyment of sexuality increases after women learn that sexuality is healthy. Also, the learning session may equip women to reformulate their attitudes to embrace the full experience of sexuality in regard to sexual pleasure.

\section{Specific Measures}

\section{Management of Female Sexual Desire|Arousal Dysfunction}

Medical interventions should be supported by evidencebased data. The management of women with sexual desire/arousal dysfunction must take into account that this disorder may arise from organic and/or psychical factors ${ }^{45}$ (-Fig. 2). Sexual desire disorder is the most frequent complaint among women with sexual problems. ${ }^{54}$ Obstetricians and gynecologists should stress the fact that a creative and romantic dyadic relationship motivates couples to engage in sexual relations and correlates with sexual satisfaction. ${ }^{55}$ However, long-term relationships may reduce the spontaneous sexual desire and sexual thoughts in women. ${ }^{56}$ In our experience, this condition is highly prevalent in women with sexual complaints in the gynecology setting.

\section{Testosterone Use for Sexual Desire Disorder}

A recent study investigated the common clinical practices of specialists regarding androgen therapy for women; $88 \%$ of physicians recognized a correlation between testosterone levels and sexual desire in women, and half of them were likely to prescribe testosterone for pre and postmenopausal women with sexual desire disorder. ${ }^{57}$ Clinical trials have consistently demonstrated that transdermal testosterone therapy improves sexual function and sexual satisfaction in women who have been assessed as having hypoactive sexual desire disorder, and in those who have suffered dramatic changes in their sex drive due to low androgen levels after bilateral ovary removal. ${ }^{58}$ However, endogenous testosterone levels did not predict sexual desire disorder and response to therapy. ${ }^{59}$ Nevertheless, high physiological doses of transdermal androgens are effective for the treatment of hypoactive sexual desire disorder (HSDD) in postmenopausal women and women in their late reproductive years. ${ }^{58}$ 


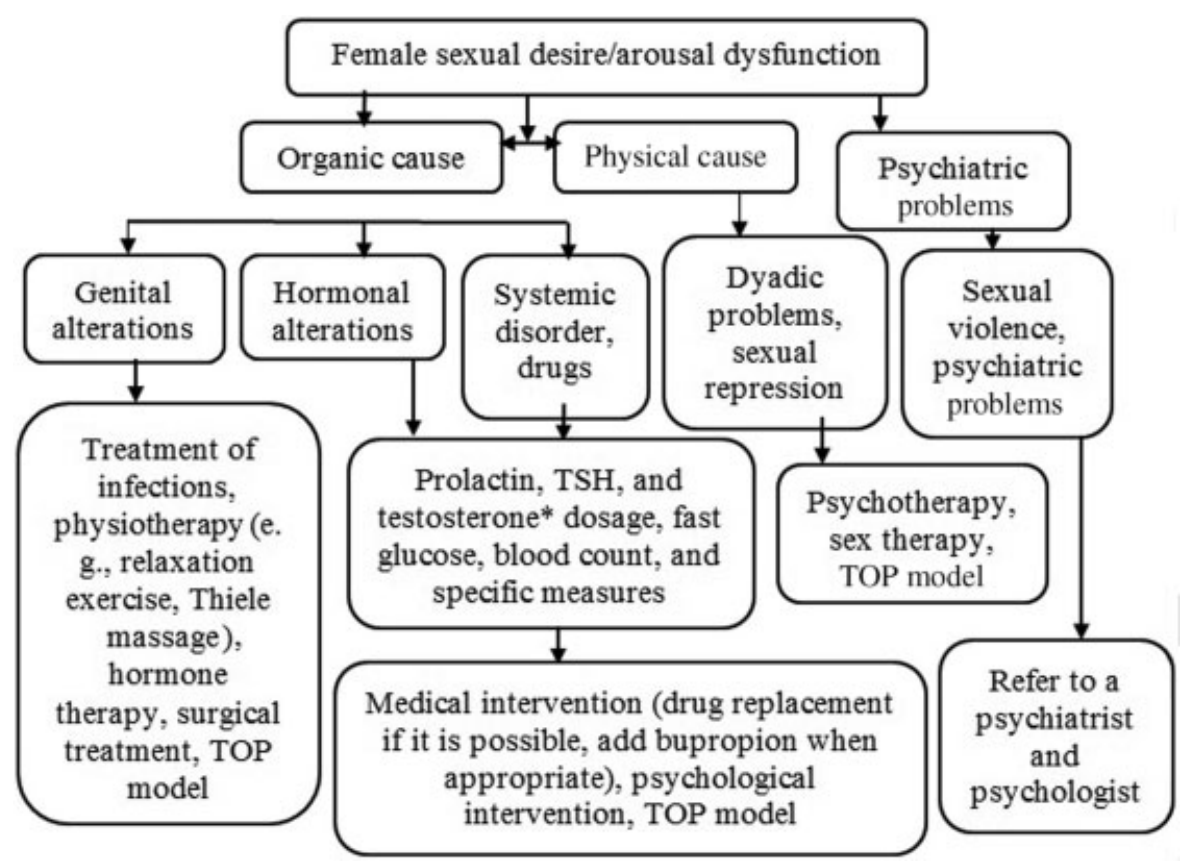

Fig. 2 Proposed algorithm for the management of female sexual desire/arousal dysfunction.

Abbreviations: TOP, Teaching $(\mathrm{T})$ the sexual response, Orienting $(\mathrm{O})$ women toward sexual health, Permitting ( $\mathrm{P})$ and stimulating sexual pleasure; TSH, thyroid stimulating hormone. *Baseline testosterone dosage for women eligible for testosterone therapy.

The problem is that physiological testosterone preparations are not available for women, testosterone preparation is off-label ${ }^{59,60}$ (- Table 2 ), and the possibility of overuse exists. Thus, the assessment of testosterone levels at baseline is recommended to identify possible overuse. As recommended previously, baseline lipid profile, baseline liver enzyme levels, and mammography should be taken. Testosterone measures after 3 to 6 weeks of the initial treatment, and every 6 months, are also recommended to assess patient overuse. $^{59}$

\section{Management of Orgasm Disorder}

The clitoris seems to be the most important anatomic structure to female orgasm (FO), ${ }^{65}$ which can occur in women when the clitoris is effectively stimulated during masturbation, oral sex, anal intercourse, partner masturbation, or during vaginal intercourse. ${ }^{66}$ Orgasm disorder is defined as a persistent or recurrent delay in, or absence of, orgasm following a normal sexual excitement phase. ${ }^{67}$ As many as $20-30 \%$ of women reported an inability to orgasm during sexual intercourse. ${ }^{68}$ Anorgasmia can occur after prolapse and urinary incontinence, and after surgical treatment due to alteration in sensitivity of the distal posterior and distal anterior parts of the vaginal wall. ${ }^{69}$ Moreover, predictors of orgasmic difficulty in women within the context of a partnered sexual experience include arousal issues, levels of distress, and latency to orgasm. ${ }^{70}$

The clinical holistic medicine is an effective intervention to treat sex orgasm disorder. ${ }^{71}$ At this level, women with anorgasmia can receive education that involves knowledge on genital anatomy, acceptance through touch and sexual fantasies, masturbation techniques, as well as acceptance of a clitoral vibrator. The use of testosterone as well as tibolone ${ }^{72}$ may improve orgasm domains ${ }^{23}$ (-Fig. 3).

\section{Management of Genito-Pelvic Pain/Penetration Disorder}

The DSM-5 brought dyspareunia and vaginismus under the common heading of genito-pelvic pain/penetration disorder. The diagnosis criteria for this disorder require at least six

Table 2 Testosterone schema associated with systemic/local estrogen therapy for women with hypoactive sexual desire disorder

\begin{tabular}{|l|l|}
\hline Formulation & Frequency of use \\
\hline Testosterone propionate $2 \%$ in petrolatum or pentravan $0.5 \mathrm{mg}$ & Vaginal; daily $^{61}$ \\
\hline Testosterone propionate $2 \mathrm{mg}$ in $0.5 \mathrm{~g}$ of a neutral cream & Vaginal; daily $^{62}$ \\
\hline $\begin{array}{l}\text { Testosterone cream } 1 \mathrm{~g} \text { per application containing } 300 \mu \mathrm{g} \text { tes- } \\
\text { tosterone propionate prepared using testosterone micronized } \\
\text { powder in an emollient cream with silicone }\end{array}$ & ${\text { Vaginal; three times a } \text { week }^{63}}^{\text {Testosterone } 300 \mu \mathrm{g} \text { in patch or pentravan in pump }}$ \\
\hline
\end{tabular}




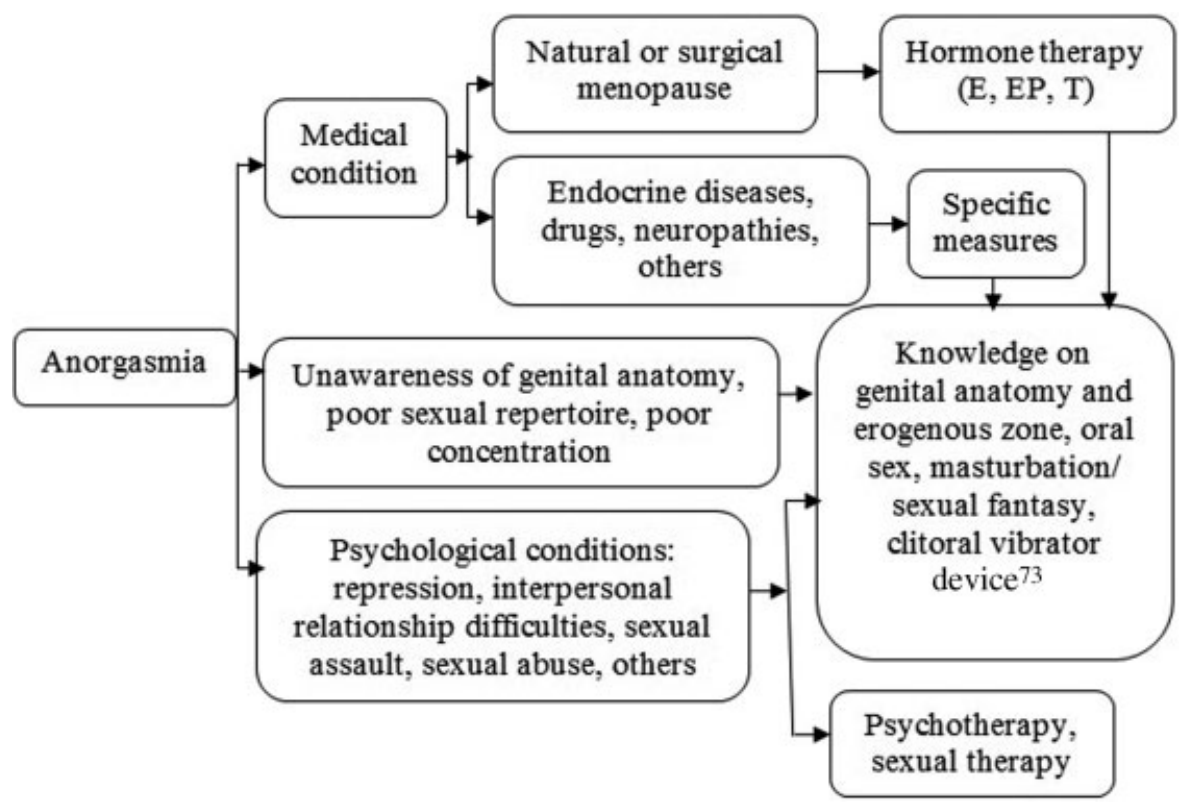

Fig. 3 Proposed algorithm for the management of female anorgasmia. Abbreviations: $E$, estradiol; $E P$, estradiol + progesterone; $T$, testosterone. ${ }^{73}$

months of duration of persistent or recurrent difficulties with one or more of the following: marked vulvovaginal or pelvic pain during vaginal intercourse or penetration attempts; marked fear or anxiety about vulvovaginal or pelvic pain in anticipation of, during, or as a result of vaginal penetration; and marked tensing or tightening of the pelvic floor muscles during attempted vaginal penetration that causes significant distress in the individual. Some conditions should be excluded, such as: nonsexual psychiatric disorders; medical conditions (lichen sclerosus, pelvic inflammatory disease, endometriosis, and vulvovaginal atrophy, for example), substance abuse, and the use of certain medications. ${ }^{74,75}$

A thorough evaluation should be made by an experienced gynecologist, including the history of duration and characteristics of the pain, as well as a physical examination to differentiate superficial dyspareunia and deep dyspareunia. If the diagnosis of vulvodynia is likely, general measures, such as genital care and hygiene, as well as the use of local anesthetics and some antidepressants and anticonvulsants, should be taken. ${ }^{76}$ In cases of deep dyspareunia, organic causes such as endometriosis and pelvic inflammatory disease should be taken into consideration, ${ }^{77}$ as mentioned before.

There is an important relationship between pelvic floor muscle dysfunction and genital pelvic pain penetration. The pelvic floor is formed by the lifter muscles of the anus (pubococcygeus, puborectalis and iliococcygeus) and the ischiococcygeus muscles, which are responsible for maintaining urinary and fecal continence; ${ }^{78,79}$ they also participate in sexual intercourse and the partum. ${ }^{80,81}$ Biomechanical changes, in turn, lead to overload of the pelvic floor muscles, favoring the onset of tender points, stiffness (spasm), contraction and inability of relaxation, ${ }^{82}$ contribut- ing to the manifestation of genitourinary pelvic pain. Surgical intervention such as the combination of Burch colposuspension and posterior colporrhaphy is likely to result in dyspareunia. $^{83}$

The management of genito-pelvic pain/penetration disorder may include digital palpation to allow the women to become aware of their pelvic floor muscles, ${ }^{84}$ muscle relaxation intervention, ${ }^{81}$ treatment of medical conditions, as well as a biopsychosocial approach and psychotherapy, ${ }^{75,85}$ especially for victims of sexual violence (-Fig. 4).

\section{Discussion}

Doctors who routinely ask about sexual complaints in their offices state that $50 \%$ of their female patients refer sexual problems. $^{90}$ Thus, Ob-Gyn professionals should routinely assess female sexual problems. ${ }^{91}$ However, a previous research has indicated that both patients and doctors experience difficulties when talking about sexuality, and that the doctor often feels ill-equipped because of the lack of established protocols valuable for the treatment of sexual complaints and dysfunctions. ${ }^{13}$ Moreover, most physicians argue about the lack of time to obtain relevant information for the clinical practice and to deal with sexual health issues; they were perceived as barriers in initiating a discussion with the patient. ${ }^{35}$ Effective training is needed for professionals, to encourage dialogue about sexual health and to identify women who have sexual dysfunctions and offer them treatment. ${ }^{2}$ Additional evidence-based educational and didactic activities would enhance the Ob-Gyn professionals' knowledge and confidence in treating sexual issues. ${ }^{17}$

It is strongly recommended that health professionals should include a sexuality approach in their routine engagement with patients, as sexual health problems are prevalent 


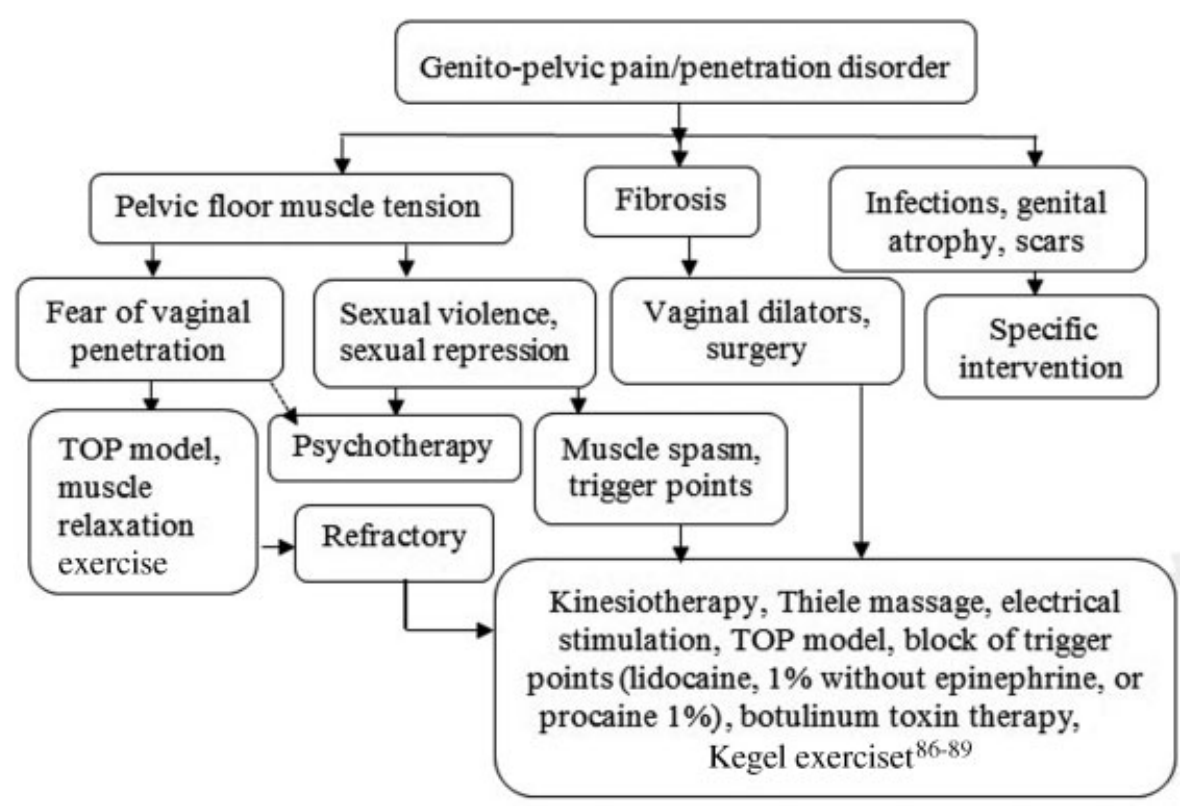

Fig. 4 Proposed algorithm for the management of genito-pelvic pain / penetration disorder in women. ${ }^{86-89}$

Abbreviation: TOP, Teaching $(T)$ the sexual response, Orienting $(O)$ women toward sexual health, Permitting $(P)$ and stimulating sexual pleasure.

in women attending primary care clinics, where one in four women are at high risk of female sexual dysfunction. ${ }^{92}$ It is recommend that the sexual history be based on three main topics, which serve as underpinning for the management of sexual problems: $i$ ) an approach centered on the person; $i$ ) evidence-based recommendations for diagnosis and treatment; and iii) use of a managed and unified approach. ${ }^{93}$ This approach is essential to enable the early diagnosis of female sexual dysfunction, as well as to guarantee sexual rights for women.

Various validated instruments for the diagnosis of sexual dysfunction are available, and can help physicians identify it according to the classifications of the American Psychiatric Association (DSM-5). ${ }^{20,94}$ However, most instruments are complex and designed to be applied by professionals with expertise in the area of sexuality, for specific situations, time or post treatment controls. ${ }^{95}$ Nevertheless, doctors should ask at least one or two questions, such as: How is your sex life? Do you have a problem you would like to discuss? ${ }^{93}$

The use of protocols makes it easier to overcome certain barriers, since they provide the beginning of a dialogue. These can potentially provide more sensitive and accurate measurements of the complex and subjective aspects of the sexual function of women. ${ }^{93}$ Information provided by the gynecologist on the biological, psychological, and social aspects of sexual function may help the patient better assess her sex life and verbalize complaints that can be addressed by the gynecologist. Additionally, many women with sexual complaints, but who do not fulfill the criteria for the diagnosis of sexual dysfunction can be helped by basic measures taken by a professional. The model presented here may guide gynecologists in their attempts to improve the sexual health of their patients.

It is important to highlight that some conditions related to female sexual dysfunction deserve a more appropriate intervention. For example, taboos concerning sexuality are common and prevent women from seeking professional help if sexual problems are encountered; ${ }^{96}$ such taboos even permeate the clinical environment, resulting in significant negative effects on both general and sexual health. ${ }^{19,97,98}$ Moreover, in some modern societies, ${ }^{99}$ sexual activity remains associated with immorality, resulting in the continued repression of sexual expression, ${ }^{100}$ especially for women, and in cases of gender violence. ${ }^{101}$ Furthermore, some religions associate sexual activity with sin, and discourage the free expression of sexual relations, except as required for procreation. ${ }^{19,102,103}$ All of these patients should be offered an interdisciplinary approach with a physiotherapist and a psychotherapist.

Cardiovascular disease, dyslipidemia, or diabetes mellitus may also be considered as early symptoms of the underlying disease, in which case the diagnosis serves as sentinel complementary actions. ${ }^{104}$ Drugs, depression, surgery and trau$\mathrm{ma}$ in the pelvic region are factors that are frequently associated with sexual difficulties in women. ${ }^{105}$ Sexual abuse may have physical and emotional implications for women, ${ }^{106}$ who are at high risk for depression, anxiety, worries, loneliness, low quality of life, ${ }^{107}$ as well as sexual problems. ${ }^{108}$ The interventions in these cases may require an interdisciplinary approach.

\section{Conclusion}

The use of protocols may provide an effective approach to deal with female sexual dysfunction in gynecological offices.

\section{References}

1 Hedelin H, Abramsson L. [Sexuality-an important factor for quality of life. Who should treat erectile dysfunction?] Lakartidningen 1997;94(28-29):2548-2552 
2 Clegg M, Towner A, Wylie K. Should questionnaires of female sexual dysfunction be used in routine clinical practice? Maturitas 2012;72(02):160-164

3 Benagiano G, Carrara S, Filippi V. Social and ethical determinants of human sexuality: 1 . The need to reproduce. Minerva Ginecol 2010;62(04):349-359

4 Benagiano G. Joseph W. Goldzieher and the birth of hormonal contraception. Contraception 2010;82(02):119-124

5 Gupta GR, Weiss E, Whelan D. Male-female inequalities result in submission to high-risk sex in many societies. Special report: women and HIV. AIDS Anal Afr 1995;5(04):8-9

6 Dialmy A. Sexuality and Islam. Eur J Contracept Reprod Health Care 2010;15(03):160-168

7 Abdo CH, Oliveira WM Jr, Moreira ED Jr, Fittipaldi JA. Prevalence of sexual dysfunctions and correlated conditions in a sample of Brazilian women-results of the Brazilian study on sexual behavior (BSSB). Int J Impot Res 2004;16(02):160-166

8 Lara LA, Coelho Neto MdeA, Martins WdeP, Ferriani RA, Navarro PA. Assessment of sexual function in infertile women in a gynecological care setting. J Sex Med 2016;13(06):938-944

9 Higgins A, Barker P, Begley CM. Sexuality and mental health nursing in Ireland: weaving the veil of socialised inhibition. Nurse Educ Today 2009;29(03):357-364

10 Sohn W. [Pleasure and pain in sexual relations. The basis and reasons for sex counseling by the general practitioner]. MMW Fortschr Med 2003;145(46):37-40

11 Nusbaum MR, Gamble G, Skinner B, Heiman J. The high prevalence of sexual concerns among women seeking routine gynecological care. J Fam Pract 2000;49(03):229-232

12 Nusbaum MR, Singh AR, Pyles AA. Sexual healthcare needs of women aged 65 and older. J Am Geriatr Soc 2004;52(01):117-122

13 Abdolrasulnia M, Shewchuk RM, Roepke N, et al. Management of female sexual problems: perceived barriers, practice patterns, and confidence among primary care physicians and gynecologists. J Sex Med 2010;7(07):2499-2508

14 Laski L, Wong S. Addressing diversity in adolescent sexual and reproductive health services. Int J Gynaecol Obstet 2010;110 (Suppl):S10-S12

15 Glasier A, Gülmezoglu AM, Schmid GP, Moreno CG, Van Look PF. Sexual and reproductive health: a matter of life and death. Lancet 2006;368(9547):1595-1607

16 Simon JA. Low sexual desire-is it all in her head? Pathophysiology, diagnosis, and treatment of hypoactive sexual desire disorder. Postgrad Med 2010;122(06):128-136

17 Pancholy AB, Goldenhar L, Fellner AN, Crisp C, Kleeman S, Pauls R. Resident education and training in female sexuality: results of a national survey. J Sex Med 2011;8(02):361-366

18 Gilmer MJ, Meyer A, Davidson J, Koziol-McLain J. Staff beliefs about sexuality in aged residential care. Nurs Prax N Z 2010; 26(03):17-24

19 Hourton J. [The Christian ethic and sexuality]. Enfoques Aten Prim 1991;6(01):3-6

20 Basson R, Berman J, Burnett A, et al. Report of the international consensus development conference on female sexual dysfunction: definitions and classifications. J Urol 2000;163(03): 888-893

21 Clayton AH, Goldfischer ER, Goldstein I, Derogatis L, LewisD'Agostino DJ, Pyke R. Validation of the decreased sexual desire screener (DSDS): a brief diagnostic instrument for generalized acquired female hypoactive sexual desire disorder (HSDD). J Sex Med 2009;6(03):730-738

22 World Health Organization (Internet). International Statistical Classification of Diseases and Related Health Problems: ICD-10 Version: 2016. 10th Rev. 2016 [cited 2016 Jan 23]; Available from: http://apps.who.int/classifications/icd10/browse/2016/en

23 American Psychiatric Association. Diagnostic and Statistical Manual of Mental Disorders - DSM-V. 5th ed. Arlington: APA; 2013
24 Annon J. Behavioral treatment of sexual problems. New York: Harper \& Row; 1976. vol. 1

25 Aslan E, Komurcu N, Beji NK, Yalcin O. Bladder training and Kegel exercises for women with urinary complaints living in a rest home. Gerontology 2008;54(04):224-231

26 Kingsberg SA, Woodard T. Female sexual dysfunction: focus on low desire. Obstet Gynecol 2015;125(02):477-486

27 Carvalheira AA, Brotto LA, Leal I. Women's motivations for sex: exploring the diagnostic and statistical manual, fourth edition, text revision criteria for hypoactive sexual desire and female sexual arousal disorders. J Sex Med 2010;7(4 Pt 1):1454-63

28 Basson R. Women's sexual dysfunction: revised and expanded definitions. CMAJ 2005;172(10):1327-1333

29 Basson R, Leiblum S, Brotto L, et al. Definitions of women's sexual dysfunction reconsidered: advocating expansion and revision. J Psychosom Obstet Gynaecol 2003;24(04):221-229

30 Jayne C, Gago BA. Diagnosis and treatment of female sexual arousal disorder. Clin Obstet Gynecol 2009;52(04):675-681

31 Basson R, Wierman ME, van Lankveld J, Brotto L. Summary of the recommendations on sexual dysfunctions in women. J Sex Med 2010;7(1 Pt 2):314-326

32 Kratochvíl S. [Vaginal contractions in female orgasm]. Cesk Psychiatr 1994;90(01):28-33

33 Meston CM, Hull E, Levin RJ, Sipski M. Disorders of orgasm in women. J Sex Med 2004;1(01):66-68

34 Georgiadis JR, Kortekaas R, Kuipers R, et al. Regional cerebral blood flow changes associated with clitorally induced orgasm in healthy women. Eur J Neurosci 2006;24(11):3305-3316

35 Ishak IH, Low WY, Othman S. Prevalence, risk factors, and predictors of female sexual dysfunction in a primary care setting: a survey finding. J Sex Med 2010;7(09):3080-3087

36 Reisinger JJ. Effects of erotic stimulation and masturbatory training upon situational orgasmic dysfunction. J Sex Marital Ther 1978;4(03):177-185

37 Paterson LQ Jin ES, Amsel R, Binik YM. Gender similarities and differences in sexual arousal, desire, and orgasmic pleasure in the laboratory. J Sex Res 2014;51(07):801-813

38 Levin RJ, Both S, Georgiadis J, Kukkonen T, Park K, Yang CC. The physiology of female sexual function and the pathophysiology of female sexual dysfunction (Committee 13A). J Sex Med 2016; 13(05):733-759

39 O'Connell HE, Eizenberg N, Rahman M, Cleeve J. The anatomy of the distal vagina: towards unity. J Sex Med 2008;5(08): 1883-1891

40 O'Connell HE, Sanjeevan KV, Hutson JM. Anatomy of the clitoris. J Urol 2005;174(4 Pt 1):1189-1195

41 Salmani Z, Zargham-Boroujeni A, Salehi M, Killeen TK, MerghatiKhoei $\mathrm{E}$. The existing therapeutic interventions for orgasmic disorders: recommendations for culturally competent services, narrative review. Iran J Reprod Med 2015;13(07):403-412

42 de Lucena BB, Abdo CH. Personal factors that contribute to or impair women's ability to achieve orgasm. Int J Impot Res 2014; 26(05):177-181

43 Perlis RH, Laje G, Smoller JW, Fava M, Rush AJ, McMahon FJ. Genetic and clinical predictors of sexual dysfunction in citalopram-treated depressed patients. Neuropsychopharmacology 2009;34(07):1819-1828

44 Schober JM, Meyer-Bahlburg HF, Ransley PG. Self-assessment of genital anatomy, sexual sensitivity and function in women: implications for genitoplasty. BJU Int 2004;94(04): 589-594

45 Goldstein I. Current management strategies of the postmenopausal patient with sexual health problems. J Sex Med 2007;4 (Suppl 3):235-253

46 Ruether RR. Sex and the body in the Catholic tradition. Conscience 2000;20(04):2-12

47 Ruether RR. Women, sexuality, ecology, and the church. Conscience 1993;14(1-2):6-11 
48 Kirby D, Korpi M, Barth RP, Cagampang HH. The impact of the Postponing Sexual Involvement curriculum among youths in California. Fam Plann Perspect 1997;29(03):100-108

49 Few $C$. The politics of sex research and constructions of female sexuality: what relevance to sexual health work with young women? J Adv Nurs 1997;25(03):615-625

50 World Health Organization. Sexual and reproductive health: defining sexual health. Geneva: WHO; 2008

51 Pujols Y, Seal BN, Meston CM. The association between sexual satisfaction and body image in women. J Sex Med 2010;7(2 Pt 2):905-916

52 Taylor TN, Munoz-Plaza CE, Goparaju L, et al. "The pleasure is better as I've gotten older": sexual health, sexuality, and sexual risk behaviors among older women living with HIV. Arch Sex Behav 2016; [Epub ahead of print]

53 Opara PI, Eke GK, Akani NA. Mothers perception of sexuality education for children. Niger J Med 2010;19(02):168-172

54 Bronner G, Etran E, Schachter B, Lavee S, Galin A, Raviv G. [Contribution of psychosexual approach to assessment and treatment of sexual dysfunction: a working model]. Harefuah 2009;148(09):595-599, 658

55 Pascoal PM, Narciso IdeS, Pereira NM. What is sexual satisfaction? Thematic analysis of lay people's definitions. J Sex Res 2014;51(01):22-30

56 Rosen RC, Maserejian NN, Connor MK, Krychman ML, Brown CS, Goldstein I. Characteristics of premenopausal and postmenopausal women with acquired, generalized hypoactive sexual desire disorder: the Hypoactive Sexual Desire Disorder Registry for women. Menopause 2012;19(04):396-405

57 Lowenstein L, Shechter A, Porst H, Tripodi F, Reisman Y. Physicians' attitudes towards androgen replacement therapy for male and female sexual dysfunction. Int J Impot Res 2016;28(02): 57-60, quiz 60-61

58 Davis SR, Worsley R, Miller KK, Parish SJ, Santoro N. Androgens and Female Sexual Function and Dysfunction-Findings From the Fourth International Consultation of Sexual Medicine. J Sex Med 2016;13(02):168-178

59 Wierman ME, Arlt W, Basson R, et al. Androgen therapy in women: a reappraisal: an Endocrine Society clinical practice guideline. J Clin Endocrinol Metab 2014;99(10):3489-3510

60 Phillips NA. Female sexual dysfunction: evaluation and treatment. Am Fam Physician 2000;62(01):127-136, 141-142

61 Emhardt E, Siegel J, Hoffman L. Anatomic variation and orgasm: Could variations in anatomy explain differences in orgasmic success? Clin Anat 2016;29(05):665-672

62 Apperloo M, Midden M, van der Stege J, Wouda J, Hoek A, Weijmar Schultz W. Vaginal application of testosterone: A study on pharmacokinetics and the sexual response in healthy volunteers. J Sex Med 2006;3(03):541-549

63 Fernandes T, Costa-Paiva LH, Pinto-Neto AM. Efficacy of vaginally applied estrogen, testosterone, or polyacrylic acid on sexual function in postmenopausal women: a randomized controlled trial. J Sex Med 2014;11(05):1262-1270

64 Simon J, Braunstein G, Nachtigall L, et al. Testosterone patch increases sexual activity and desire in surgically menopausal women with hypoactive sexual desire disorder. J Clin Endocrinol Metab 2005;90(09):5226-5233

65 Puppo V, Puppo G. Anatomy of sex: Revision of the new anatomical terms used for the clitoris and the female orgasm by sexologists. Clin Anat 2015;28(03):293-304

66 American Psychiatric Association. Diagnostic and statistical manual of mental disorders: DSM-IV-TR. 4th ed. Washington, DC: APA; 2000

67 Harris JM, Cherkas LF, Kato BS, Heiman JR, Spector TD. Normal variations in personality are associated with coital orgasmic infrequency in heterosexual women: a population-based study. J Sex Med 2008;5(05):1177-1183
68 Lakeman MM, van der Vaart CH, Laan E, Roovers JP. The effect of prolapse surgery on vaginal sensibility. J Sex Med 2011;8(04): 1239-1245

69 Rowland DL, Kolba TN. Understanding orgasmic difficulty in women. J Sex Med 2016;13(08):1246-1254

70 Struck P, Ventegodt S. Clinical holistic medicine: teaching orgasm for females with chronic anorgasmia using the Betty Dodson method. Sci World J 2008;8:883-895

71 Wu MH, Pan HA, Wang ST, Hsu CC, Chang FM, Huang KE. Quality of life and sexuality changes in postmenopausal women receiving tibolone therapy. Climacteric 2001;4(04):314-319

72 Davis SR, Moreau M, Kroll R, et al; APHRODITE Study Team. Testosterone for low libido in postmenopausal women not taking estrogen. N Engl J Med 2008;359(19):2005-2017

73 Ishak WW, Bokarius A, Jeffrey JK, Davis MC, Bakhta Y. Disorders of orgasm in women: a literature review of etiology and current treatments. J Sex Med 2010;7(10):3254-3268

74 Faubion SS, Rullo JE. Sexual dysfunction in women: a practical approach. Am Fam Physician 2015;92(04):281-288

75 Haefner HK, Collins ME, Davis GD, et al. The vulvodynia guideline. J Low Genit Tract Dis 2005;9(01):40-51

76 Binik YM. The DSM diagnostic criteria for dyspareunia. Arch Sex Behav 2010;39(02):292-303

77 Shishido K, Peng Q Jones R, Omata S, Constantinou CE. Influence of pelvic floor muscle contraction on the profile of vaginal closure pressure in continent and stress urinary incontinent women. J Urol 2008;179(05):1917-1922

78 Thompson JA, O'Sullivan PB, Briffa NK, Neumann P. Assessment of voluntary pelvic floor muscle contraction in continent and incontinent women using transperineal ultrasound, manual muscle testing and vaginal squeeze pressure measurements. Int Urogynecol J Pelvic Floor Dysfunct 2006;17(06):624-630

79 Meyer S, Salchli F, Bettaieb H, et al. [The peripheral sexual response ... from urogynecology to sexology]. Rev Med Suisse 2015;11(498):2320-2325

80 Kolberg Tennfjord M, Hilde G, Staer-Jensen J, Siafarikas F, Engh $\mathrm{ME}, \mathrm{B} \emptyset \mathrm{K}$. Effect of postpartum pelvic floor muscle training on vaginal symptoms and sexual dysfunction-secondary analysis of a randomised trial. BJOG 2016;123(04):634-642

81 Strauss C, Lienemann A, Spelsberg F, Bauer M, Jonat W, Strauss A. Biomechanics of the female pelvic floor: a prospective trail of the alteration of force-displacement-vectors in parous and nulliparous women. Arch Gynecol Obstet 2012;285(03):741-747

82 Weber AM, Walters MD, Piedmonte MR. Sexual function and vaginal anatomy in women before and after surgery for pelvic organ prolapse and urinary incontinence. Am J Obstet Gynecol 2000;182(06):1610-1615

83 Amuzu BJ. Nonsurgical therapies for urinary incontinence. Clin Obstet Gynecol 1998;41(03):702-711

84 Thomas HN, Thurston RC. A biopsychosocial approach to women's sexual function and dysfunction at midlife: A narrative review. Maturitas 2016;87:49-60

85 Abdo CHN, Oliveira WM Junior. O ginecologista brasileiro frente às queixas sexuais femininas: um estudo preliminar. RBM Rev Bras Med 2002;59(03):179-186

86 Alvarez DJ, Rockwell PG. Trigger points: diagnosis and management. Am Fam Physician 2002;65(04):653-660

87 Fageeh WM. Different treatment modalities for refractory vaginismus in western Saudi Arabia.J Sex Med 2011;8(06):1735-1739

88 Kegel AH. Early genital relaxation; new technic of diagnosis and nonsurgical treatment. Obstet Gynecol 1956;8(05):545-550

89 Kegel AH. Stress incontinence of urine in women; physiologic treatment. J Int Coll Surg 1956;25(4 Part 1):487-499

90 Collier F, Cour F. [How to manage a woman with a sexual complaint in clinical practice?] Prog Urol 2013;23(09):612-620

91 Alarcão V, Ribeiro S, Miranda FL, et al. General practitioners' knowledge, attitudes, beliefs, and practices in the management 
of sexual dysfunction-results of the Portuguese SEXOS study. J Sex Med 2012;9(10):2508-2515

92 Althof SE, Rosen RC, Perelman MA, Rubio-Aurioles E. Standard operating procedures for taking a sexual history. J Sex Med 2013; 10(01):26-35

93 Vroege JA, Gijs L, Hengeveld MW. Classification of sexual dysfunctions: towards DSM-V and ICD-11. Compr Psychiatry 1998; 39(06):333-337

94 Giraldi A, Rellini A, Pfaus JG, et al. Questionnaires for assessment of female sexual dysfunction: a review and proposal for a standardized screener. J Sex Med 2011;8(10):2681-2706

95 Berman L, Berman J, Felder S, et al. Seeking help for sexual function complaints: what gynecologists need to know about the female patient's experience. Fertil Steril 2003;79(03):572-576

96 Allen D. Sexuality and patients: breaking the last taboo. Nurs Stand 2000;14(32):23

97 Ramirez S. Early sexual experience and traditional values in Colombia. Newsl Womens Glob Netw Reprod Rights 1991; 36(36):30-31

98 Hendrickx K, Lodewijckx E, Van Royen P, Denekens J. Sexual behaviour of second generation Moroccan immigrants balancing between traditional attitudes and safe sex. Patient Educ Couns 2002;47(02):89-94

99 Goodson P, Edmundson E. The problematic promotion of abstinence: an overview of Sex Respect. J Sch Health 1994;64(05): 205-210
100 Pai HC, Lee S, Chang T. Sexual self-concept and intended sexual behavior of young adolescent Taiwanese girls. Nurs Res 2010; 59(06):433-440

101 Benagiano G, Carrara S, Filippi V. Social and ethical determinants of human sexuality: 2. Gender-based violence. Eur J Contracept Reprod Health Care 2010;15(04):220-231

102 Benagiano G, Mori M. The origins of human sexuality: procreation or recreation? Reprod Biomed Online 2009;18(Suppl 1):50-59

103 Campbell MM, Stein DJ. Sexual dysfunction: A systematic review of South African research. S Afr Med J 2014;104(06):440-444

104 Clayton AH, Balon R. The impact of mental illness and psychotropic medications on sexual functioning: the evidence and management. J Sex Med 2009;6(05):1200-1211, quiz 1212-1213

105 Ben-Amitay G, Kimchi N, Wolmer L, Toren P. Psychophysiological reactivity in child sexual abuse. J Child Sex Abuse 2016;25(02): 185-200

106 Kamiya Y, Timonen V, Kenny RA. The impact of childhood sexual abuse on the mental and physical health, and healthcare utilization of older adults. Int Psychogeriatr 2016;28(03):415-422

107 Khan N. Sexual and physical abuse: a threat to reproductive and sexual health. Sex Health Exch 1998;1(01):1-3

108 Raghunandan C, Agrawal S, Dubey P, Choudhury M, Jain A. A comparative study of the effects of local estrogen with or without local testosterone on vulvovaginal and sexual dysfunction in postmenopausal women. J Sex Med 2010;7(03): $1284-1290$ 